\title{
Self help groups: the fourth estate in medicine?
}

\author{
STEPHEN LOCK
}

\author{
Who guide them not by Good Counsel, \\ All in vain is their travail \\ And finally fortune shall them fail \\ And bring them to confusion.
}

SIR DAVID LINDSAY,

Satyre of the Three Estates (1568).

Here I suggest that we should recognise the rapidly growing contribution made by the many lay self help groups. I believe that we should add these as the fourth estate in medicine to Sir Theodore Fox's "greater medical profession." To try to make up my own mind about the role of self help groups I saw some dozen people directly concerned with them and read some of the excellent academic analyses..$^{2-5} \mathrm{I}$ looked at many of their publications and also circulated almost 70 doctors from the $B M \mathcal{Y}$ 's list of referees with a questionnaire asking them about their knowledge of, as well as their attitudes towards, these groups.

How does one define self help groups? Some of the definitions are long and intricate, some refer back to Samuel Smiles and Prince Kropotkin - two authors I haven't read and don't intend to readand some would cover groups devoted purely to one purpose, such as the Patients' Association, the College of Health, and Action on Smoking and Health. The composite definition I've arrived at is: "A self help group is a voluntary organisation, usually of peers, who have come together for mutual help and support, in satisfying a common need, overcoming a common handicap or life disrupting problem, and bringing about desired social or personal change, or both."

There are now at least 1500 national self help organisations and over 25000 regional branches. Clearly, no one is "typical", but let's look at one as an example. I've chosen the National Eczema Society for several reasons: partly because its national office is just above mine in London; partly because it's middle of the road in its policies; and partly because I happen to know one of the medical advisers. The society was started in 1975, after a mother of an 8 year old had written to the Guardian. ${ }^{6}$ She suggested, among other things, "Perhaps we should form a society for sufferers and their relatives."

This letter provoked hundreds of letters from patients, nurses, and relatives. With the help of the National Council for Social Service a meeting was held in London in July, only two months after the original suggestion. This formed local groups and appointed a steering committee to set up a national organisation.

Today the National Eczema Society has a central London office, with four full time and two part time staff. Its annual budget is $£ 120000$, made up of subscriptions and donations. There are over 200 peripheral autonomous groups, and it's run by a board of management composed entirely of non-professionals-although there is a medical advisory panel. The society concentrates on giving advice, such as on diet and steroids, and on funding research. At the annual summer holiday for children with eczema they are advised on bathing routines and the proper use of moisturisers and steroids.

In its policy the society is orthodox-for example, it does not recommend goats' milk as a sovereign remedy for eczema. On the

British Medical Journal, London WC1H 9JR

STEPHEN LOCK, MB, FRCP, editor

Based on the Maurice Bloch lecture, given at the University of Glasgow on 27 November 1986. other hand, almost "anything goes" in the correspondence columns of its newsletter, and people can write in with all sorts of suggestions.

\section{History}

Self help groups are often, and rightly, thought of as a recent, and certainly postwar, development. But it is well to remember that two highly successful organisations, Alcoholics Anonymous and the British Diabetic Association, are both over 50 years old. They are also thought of as being started by non-professionals, but in fact doctors have been concerned in the formation of about a third and, after all, Alcoholics Anonymous was founded through the meeting in Akron, Ohio, of Bill Wilson, a New York stockbroker, and Bob Smith, an Ohio doctor who had managed to get through the entire day of 10 June 1935 without having a drink.

There are some common background factors to the formation of these self help groups: a more educated population, less money for health, an increase in chronic illnesses, and the trend towards community participation in health. Nevertheless, the main impetus has been the perceived failure of the professional caregivers to meet the needs of particular groups of patients. Thus, discussing the needs of patients with a stoma, an article on ostomy associations states that: "with a few honourable exceptions, the medical and nursing professions failed to comprehend fully their sense of social isolation, stigmatism, and being overwhelmed by what was described as a "living hell." " 8 Another observer has suggested that no true self help group has ever arisen to provide a service that was already obtainable through the medical system. ${ }^{9}$ So it's not unexpected to find that many groups were founded by sufferers or their relatives, and that several years later these have a dominant role in their governing bodies. Once the groups have been started, then, health professionals have at the most an advisory role, the amount and importance of which vary with the group.

I would argue that no individual professional could have been expected to comprehend the details of the vast range of practical problems and psychological sorrows that sufferers and their relatives experience. How can, say, a GP in his surgery have the time and the insight to fulfil the widely different needs of the relatives of a patient with Huntington's chorea, a woman who's just had a mastectomy, and a child with serious congenital heart disease? As Dr Vicky Clement-Jones, a doctor with ovarian cancer who herself founded the British Association for Cancer United Patients and their Family and Friends, has said: "I realised that other patients could give me something unique which I could not obtain from my doctor or nurses, however caring." 10 The unique feature is the shared experience of different ways of coping with disease. And I believe that it is largely this freedom from professional domination that has given most groups their characteristics of spontaneity, vitality, innovativeness, and flexibility. It has also restored to them something that both Ivan Illich and Ian Kennedy claim has been taken away by professional caregivers: patients' involvement in the management of their own illness.

So, with or without professional assistance, self help groups are usually formed by laymen to meet a need-and this need may be reflected as the dominant role of the eventual organisation. As I see it, these groups are extremely varied, but they have five possible main roles. Firstly, information-which may be aimed at patients and relatives or other carers. Sometimes the information is for professionals, such as the teach ins by experts at postgraduate medical centres that the Multiple Sclerosis Society organises for GPs. Sometimes the information is for people who are frightened 
that they may have a disease-say AIDS - which is one role taken by the Terrence Higgins Trust. When the information is medical advice for patients it is usually derived from the consensus view of a professional advisory panel-for example, facts on treatment given by the National Eczema Society. For patients and their carers such information is given in several obvious ways-specifically, often on the telephone, and more generally at meetings; and by the society's own newsletter, magazines, and books. What arresting and informative leaflets many of these are. For the public information can be given through articles in the press and features on radio and television.

Some societies supplement orthodox care by organising "clinical" sessions - for example, those held at a swimming pool by a London asthma support group. ${ }^{11}$ Here the physiotherapist shows the children how to take their medication properly and gives graded exercises tailored to each child, and breathing exercises in the pool. Residential courses are a feature of care in Norway, where the Frambu Centre, just outside Oslo, offers fortnightly courses for children and adults concerning 20 different categories of rare, often congenital or hereditary disorders. They include achondroplasia, bladder exstrophy, haemophilia, Huntington's chorea, and retinitis pigmentosa. ${ }^{12}$

Inevitably this information function is mixed with the second role: welfare. The value of a fortnight's holiday for the sufferer may be compounded by the respite given to a full time carer of, say, somebody with Huntington's chorea or multiple sclerosis. But usually meeting somebody else who has got the same problem is one rapid and effective way of diminishing stress and getting advice based on personal experience. This kind of contact will deal with one of the most difficult tasks: to cope with the stigma of the condition, changing self perception through realising that others have succeeded in coping. But such advice may be applied to a wide range of conditions. For this reason Contact a Family believes that a firmer base for some groups may be neighbourhood rather than the particular type of handicap.

\section{Professional counselling}

Counselling by workers-either professionals or sufferers who have overcome the initial trauma of having, say, an ileostomy or mastectomy, and who have then been trained-is nevertheless also important for specific needs. Experts are often needed to guide people about the complex array of services on which they can draw, or to take the counselling role in special cases, such as the joint neurological/genetic clinics established for patients with Huntington's chorea and their relatives.
The third role of self help groups is "political," lobbying for better public understanding of the condition, for more funds, and for better facilities for prevention, treatment, and research. Inevitably the needs are individual to the group rather than general. Some time ago, for instance, the Ileostomy Association successfully pressurised the Department of Health to establish a training course for stoma nurses. When it began, over three years ago, the Terrence Higgins Trust emphasised the heavy load that AIDS would eventually throw on the health and social services and the need for media campaigns to try to contain the epidemic. The Association to Combat Huntington's Chorea is lobbying regional health authorities about the shift of mental care into the community, asking what specific provision is being made for patients with the disease. It believes that regions can act if they're persuaded of the rightness of a cause, whereas the government can issue only guidance, which remains guidance however strong it is.

The fourth role is research, and for some groups this function may be dominant: the Multiple Sclerosis Society, for example, is now third in the league of spending on research, after the bodies devoted to cancer and heart disease. Indeed, currently this society now finds itself funding research that had previously been supported by bodies such as the Medical Research Council which can no longer afford to do this. Some groups were formed for the sole purpose of funding research-for example, the Crohnies, a small London based group devoted to Crohn's disease, has concerned itself exclusively with fund raising events and appeals.

On the other hand, some groups, such as the Association to Combat Huntington's Chorea, have largely abandoned supporting scientific research, finding that inevitably the returns are slow and unpredictable while the scarce funds are urgently needed for studies into the social aspects of care, such as counselling. Nevertheless, research grants are a good way of involving long term professional help. As one slightly cynical medical adviser put it to me: "it's better to back an individual rather than a project, because he'll remember the research grant all his life and always be prepared to help the society."

Finally, a few groups confine themselves to treatment. "Each [Alcoholics Anonymous] group has but one primary purpose-to carry its message to the alcoholic who still suffers.... Alcoholics Anonymous has no opinion on outside issues; hence the AA name ought never be drawn into public controversy." ${ }_{3}$

The organisation of the groups varies widely, from a small group run entirely by a housewife from her own home to a widely scattered organisation with a full time general secretary and well staffed central and regional offices. Sometimes there are numerous autonomous branches, with a centrally elected council. In turn, this is advised by several subcommittees, devoted to aspects such as

\section{Self help groups}

No of questionnaires sent

No of replies received

Knowledge of groups

No of groups known about by each person

In general $\quad 0-400(16 / 54$ who answered

In specialty this question knew $\geqslant 10)$ this question knew $<10$ )

Approval of groups

Approve of self help groups

Do not approve

Qualified approval

Use of groups

Use self help groups frequently

( $\geqslant$ once a month)

infrequently ( $<$ once a month)

Never use self help groups

Not answered
68 Opinion of groups' usefulness

64 Self help groups are not very useful quite useful useful

$$
\text { very useful }
$$

Mixed feelings

Not answered

\section{Recommending groups to patients}

Would give patients literature about groups

Would give patients groups' addresses

58 Would advise patients to go to group meetings 38

Not answered

Listing of groups

Would use groups more if list available

Would probably use groups more if list available 15

Would not

Would probably not

Would probably not, as have list already

Not answered

\section{General comments}

Positive-Doctors can learn from groups

Groups can give patients information and help that doctors have not the time or knowledge to give.

Negative-Some groups are anti-doctor

A tendency to "crankiness" among some group members

Can make patients too preoccupied with their disease

One respondent returned the questionnaire unanswered because "I do not understand the definition of 'self help' groups" 
counselling, research, fund raising, and public relations. Raising funds is a constant preoccupation; these come from a variety of sources, including individual subscriptions and donations(including legacies), appeals and charity events, and grants from charitable trusts, local authorities, and public bodies such as the Department of Health and Social Security. Some of the officials complain that a constant preoccupation with funds diverts their skills from where they would be better used. The budgets of some groups are largefor this year $£ 1 \mathrm{~m}$ for the Terrence Higgins Trust and $£ 6 \mathrm{~m}$ for the Multiple Sclerosis Society. Even so, several of the secretaries told me that donations have recently fallen off, and they postulated that there is a finite "pool" of money available for charity, much of which has recently been diverted in response to the appeals for help to the Third World.

\section{Disadvantages and advantages}

What of the disadvantages and advantages of self help groups? Some of the disadvantages are obvious. In particular, there's a danger that the groups may be run largely by the white middle class in distant middle class suburbs - but this is certainly not true of many groups, ${ }^{12}$ and a notable recent development has been the foundation of ethnic group organisations. ${ }^{13}$ For example, with the help of the National Eczema Society a Bengali Mothers Support Group for parents and children with eczema has recently been set up in the London borough of Tower Hamlets.

Snobbery again raises its ugly head in a pecking order of esteem: it may be easier to raise funds for research on a "glamorous" topic, with attractive high technology and good success rates, such as congenital heart disease, than into long term care and counselling in subjects in which success is undramatic, such as mental handicap.

Another snag is a feature of any voluntary organisation: $95 \%$ of

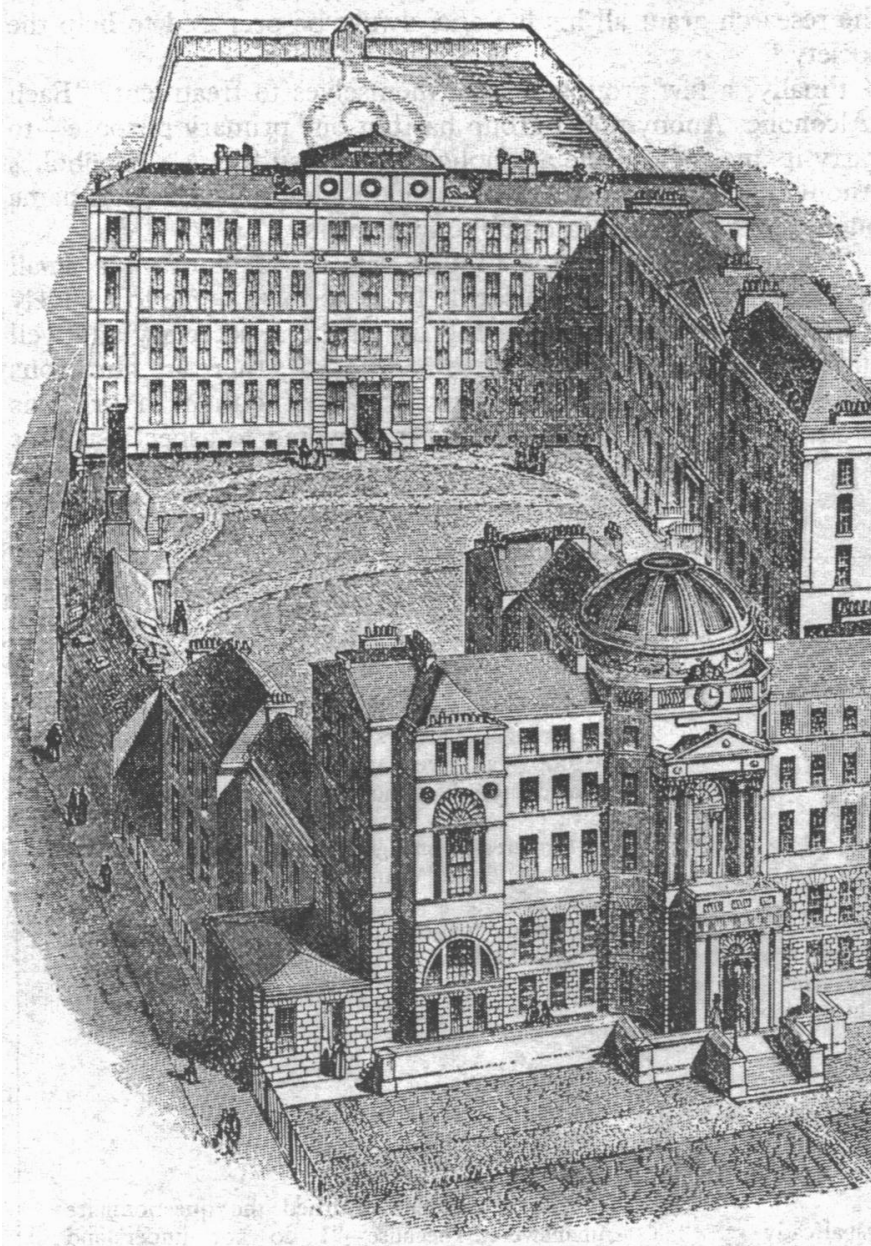

Glasgow Royal Infirmary in 1961. From J D Comrie History of Scottish Medicine (Wellcome Institute Library). the work is done by $5 \%$ of the members. One result may be that a powerful individual may become dominant or that a cohort of the founders may get out of touch with the new and younger members. A strict limit on how long anybody can hold office, or the discreet help of a professional, may overcome the former risk and a democratic structure the latter, though undoubtedly some new organisations are founded because of the intransigence of the old.

Next there is a danger that official responsibility for a part of health may be shrugged off on to the voluntary organisations. I doubt whether this is a major risk, given that most groups have been started to fill gaps in the health service that seemed unlikely to be plugged anyway. Moreover, in my researches I was impressed by the amount of discreet help given by the Department of Health and Social Security-which, though it is said to have no individual responsible for self help groups, ${ }^{14}$ does seem to have been responsive to their needs.

One feature of the recent sponsorship of groups by charitable bodies has been that they ask for an evaluation of the groups. Such monitoring may get over the final disadvantage - namely, a lack of accountability: though anyone can readily complain about a statutory service, they can't about a voluntary one. In a study in 1981 of 2080 groups in the London area Penny Webb found that only $28 \%$ answered an initial inquiry within a month and 126 failed to reply at all. ${ }^{13}$ Some telephone answering techniques lacked "social skills"- for example, she records a conversation with an alcoholic counselling service which offered help between 1000 and 1800

"What do you want? It's past five and there's no one really here who can be bothered with you."

"I've a drink problem - can you help?"

"Look, it's past five; come back on Monday."

In a Guardian interview, but not in her article, Penny Webb added, "I went into this [investigation] thinking self help groups were the best things since sliced bread, and came out thinking I would be very careful before sending my nearest and dearest to one." 15

Two further disadvantages must be mentioned. Firstly, the group may put the needs of the carers before those of the patients. I heard an anecdote of one patient with motor neurone disease who went to a meeting of a self help group (not in this country). There were no other patients there. All the members were caring for patients, and the entire session consisted of complaints about the selfishness and thoughtlessness of these patients. Needless to say,

this did nothing to help the one person there who'd got the disease, however valuable a safety valve the session may have been for the others.

Despite all this, however, and the further obvious threat that a lunatic fringe may occasionally get in on the act, I believe that the advantages of most of these groups must outweigh any disadvantages. And one of the prime advantages must be exploring the unorthodox, deviating from the party line, pursuing lateral thinking to an ultimate conclusion. Perhaps nowhere is this illustrated better than with the Action for Research into Multiple Sclerosis (ARMS), which was formed by somebody dissatisfied by the then research programme of the Multiple Sclerosis Society. The latter is run very much on the medical model advised by a research committee of professionals; rightly, in its view (just like the $B M \mathcal{F}$ with its peer review system), it tends largely to concentrate on the orthodox and likely rather than on the unorthodox and unlikely. ARMS, on the other hand, has sponsored research into the Field test for multiple sclerosis, dietary treatment, and hyperbaric oxygen. Though the Multiple Sclerosis Society did some research into the last, it abandoned it after concluding that it had no valid role. ARMS doesn't agree: it continues to offer hyperbaric oxygen treatment at one of its centres; patients, their relatives (who supervise the treatment), and some of their GPs (whose permission 
is needed) obviously welcome the hope that hyperbaric oxygen gives; and there is still sufficient medical doubt on the other side surely to justify this approach. ${ }^{16} 17$

The possibility of flexibility and innovation is nowhere shown more clearly than with the Terrence Higgins Trust. Without any official body to displease it has been able to issue leaflets in nontechnical and highly explicit language to both homosexuals and drug addicts, ensuring that these get to where they are needed-to gay bars and drugs users. It has started training social workers in the health service to cope with the expected enormous load of counselling patients with AIDS; and it has created an interfaith group to help clergy of all denominations concerned with these patients.

So where should self help groups be going? I believe, firstly, that everybody - the public, professionals, and government alikeshould recognise the valuable and special contribution that most of them are making. My questionnaire study showed certainly that many of the doctors knew about a few groups and welcomed their role, which they thought should be extended (table). Even so, the number that most respondents knew about was tiny and I wonder whether in practice they remembered the existence of these groups often enough.

Secondly, we need to be much more aware of the enormous potential need for this help "out there." By mistake the telephone number of one group wholly devoted to raising funds for research was given on a television programme. Thereafter this telephone line was continuously jammed for three days by people desperate for advice that they had not been able to get from either their own doctor or from another group-which did not reply to letters. As the line was serving a business the organisers, who had neither the time for counselling nor the skills to do so, lost an estimated $£ 10000$ worth of business. After another television programme the person behind the recently founded Raynaud's Society has been getting over 60 telephone calls a day. Yet another television programme about leaflets on cancer elicited 66 telephone calls and 255 requests within a week. And, again, Webb quotes a tearful woman concerned with a group dealing with the abuse of prescribed drugs: "People have telephoned me day and night and I can no longer cope-I don't want to get involved with anyone!"'13

Yet, given that world wide the membership of Alcoholics Anonymous is only $1-2$ million, and there are an estimated 3/4-1 million people severely damaged by alcohol in Britain alone, even if its approach is suitable for only a fraction, clearly the message is not getting across. Thus one survey showed that only $18 \%$ of people had heard of their self help organisation through their doctor or health visitor-most had learnt of it through word of mouth, newspaper, magazine, statutory organisation, or the Citizens' Advice Bureau. Anecdotally I heard of somebody visiting a patient who'd had a mastectomy in a swish private hospital; she asked the ward sister if she had the address of the Mastectomy Association. "I think I've got it somewhere," was the reply, but the address was not produced even though there were three other, similar patients in the ward at that time, who would presumably have welcomed information on bras and swimwear even if they didn't want any counselling.

\section{Source of information}

If health professionals accept this need continually to remember about self help groups, then fortunately there is no shortage of sources of information. Several useful directories and pamphlets have been produced, organisations such as Mencap and Contact a Family will provide names of groups within those disciplines they cover, and there is now a comprehensive computerised information service in Southampton. Like the ones in the USA (where self help groups have also flourished), the Southampton service can produce accurate information, often including literature, quickly and cheaply. It had 6000 inquiries in 1985, most of them from health visitors, with a growing demand, while its director, Robert Gann, has recently produced a comprehensive handbook. ${ }^{18}$

This move towards loose coordination is being mirrored else- where, especially in two bodies. One of them, Contact a Family, I have already referred to, but its new preoccupation is a telephone service that will be able immediately to put more and more families with handicapped children in touch with some self help organisation. One achievement will be that Contact a Family will be working with other large organisations such as Mencap, the Down's Children's Association, and the Spastics Society.

The second development is the National Self Help Support Centre, which has recently been established at the National Council for Voluntary Organisations in London. Funded by the King's Fund and Carnegie Trust, this will explore ways in which groups can be helped to achieve their aims and objectives, getting support from professionals and the voluntary sector while having their autonomy and independence respected. Thus it intends to develop networks of specialised groups, act as a clearing house (including producing a newsletter), and support the workers' needs, including teaching them counselling skills.

I believe, then, that the self help groups have a unique role, which they should be encouraged to develop: "Seeing a young girl with an ileostomy walk into my hospital room in a pair of tight fitting jeans with no visible sign of an appliance reassured me that I could lead a normal life. Doctors and nurses could not give me that type of help." 19

Even so, we have to remember that by no means every patient or relative will benefit from joining a group. Doctors, for instance, should be cautious about recommending a group unless they know the answers to a number of questions. What are its priorities? Is it primarily for patients or carers? Is its emphasis on counselling or research? Does it espouse alternative medicine? And so on.

My personal hope is that some self help groups will adopt a more "political" stance. One of the worrying aspects of medical care in Britain is how to persuade professionals (including official bodies and the government) to adopt the optimum line of management. There are obvious dangers to any total conformity; I also respect the rights of professionals, which are akin to those of Bagehot's constitutional monarch: "A constitutional monarch should not initiate, should not interfere, but does have three rights: to be consulted; to encourage; to warn."

Yet important lessons are being ignored, sometimes through ignorance, often through disinclination, and occasionally through sheer arrogance. Take, for example, the recent consensus conference on the management of breast cancer..$^{20}$ How long shall we have to wait until its eminently reasonable recommendations are followed, other things being equal, by most surgeons in most district general hospitals? What mechanisms, short of the courts in cases of negligence, are there for doing so? And how do we persuade the authorities to provide the badly needed funds to set up breast clinics on the lines laid down by the conference, which after all included a sizable proportion of professionals? Shrugging the shoulders is no answer, but enlisting the lobbying support of a cancer group, such as the Mastectomy Association (which currently does not take any stance on such matters), might be. In a "socialised" health service market forces have no place and the consumer is little heeded. The service has relied on community health councils to give the voice of the consumer a hearing. A few of these councils have done this job well; several have seemingly done little; and some have been hijacked for purely political purposes. But we might ask whether the structure is right, when by their nature community health councils have to deal with generalities rather than specifics. If it is thought that the consumer still needs a louder voice, additional representation by the self help groups might be one answer.

I thank Professor Bryan Jennett for his help and encouragement and the numerous people who gave me their time and advice about self help groups, particularly Mai Wann of the National Self Help Support Centre and Bob Gann, of Help for Health, Southampton.

\section{References}

1 Fox TF. The greater medical profession. Lancet 1955; ;i: $779-80$

2 Richardson A, Goodman M. Self-help and social care: mutual aid organisations in practice. London: Policy Studies Institute, 1983 
3 Robinson D. Talking out of alcoholism. London: Croom Helm, 1979.

4 Miller N. Setting up for self-help. London: Contact a Family and the Mental Health Foundation, 1984.

5 Hatch S, Hinton T. Self-help in practice: a study of Contact a Family, community work, and family support. Sheffield: Joint Unit for Social Services Research, 1986.

6 Launer J. Self-help society for eczema sufferers and their families. Br Med $\mathcal{F}$ 1976;ii: 1494-5.

7 Robinson D, Robinson Y. From self-help to health. London: Concord Books, 1979.

8 Alexander NB. Self-help groups: part 1. Clin Gastroenterol 1982;11:405-14.

Jenchs (1976). Cited by Webb PA. Ready, willing but able? The self-help group. Journal of the Royal Society of Health 1983; January:35-41.

10 Clement-Jones V. Cancer and beyond: the formation of BACUP. Br Med f 1985;291:1021-3.

11 Littlewood J. Asthma -a support group. Nursing Times 1984 August 1:40-2.
12 Vandrik IH, Storhaug K. Family-focused services for children with rare disorder, exemplified by bladder exstrophy. Clin Pediatr (Phila) 1985;24:97-100.

13 Webb PA, Ready, willing but able? The self-help group. Fournal of the Royal Society of Health 1983; January:35-41

14 Hatch S. Participation in health. In: Maxwell R, Weaver N, eds. Public participation in health London: King's Fund, 1984.

15 Melville J. Careless. Guardian 1982 April 21:17.

16 Bolt J, Perrins DJD, Webster C. Hyperbaric oxygen in multiple sclerosis. Br Med $f$ 1986;292:691

7 James PB. Hyperbaric oxygen in multiple sclerosis. Br Med f 1986;292:691.

8 Gann R. The health information handbook. Aldershot: Gower, 1986.

19 James PB. Self-help groups: part 2. Clin Gastroenterol 1982:11:415-9.

20 Anonymous. Consensus development conference: treatment of primary breast cancer. Br Med $\mathcal{F}$ 1986;293:946-7.

\title{
Searching for our moral roots
}

\author{
JOHN HABGOOD
}

It is a coincidence that our lessons this evening should have included the Ten Commandments. ${ }^{12}$ They were simply the set lessons for today's evensong. But it is a good coincidence because the commandments remind us of our moral roots. They are a foundation stone of Jewish and Christian civilisation. For thousands of years they have been regarded as the very heart of biblical morality. And so for a profession which often finds itself at the sharp end of our society's moral dilemmas the message that morality has a firm basis in God's commandments could be both encouraging and important.

The doctors among you do not need me to remind you of the appalling moral choices that you sometimes have to make. It is not for nothing that medical ethics has become a growth subject, though I notice that writings on the subject from within the profession often draw only a very thin line between ethics and etiquette. There is a potential difference between things which are professionally appropriate and things which are morally right, and it is a difference which in some circumstances may have to be watched.

But in general it is true, isn't it, that the medical profession has become burdened with more and more of people's insoluble personal problems and more and more decisions of principle which may have wide social repercussions? This is partly the consequence of your own successes. New techniques create new moral choices. In part you are trapped in the confusions of a society which is no longer sure of its own moral basis and so tries to push its decisions off on to convenient scapegoats.

A recent writer tried to imagine the kind of letters that might be published in The Times after a leading article deploring the decline in moral standards, with the usual references to violence, drugs, divorce, abortions, and so forth. Some letters would dispute the facts. What was the data base for the statistics? Some would question whether the facts, if agreed, represent a moral decline at all. Isn't it healthier that people should make their own choices, at least on matters which affect only themselves, rather than be restrained by fear of punishment or social disapproval? Others might go further and point to the shortcomings of a social system which encourages escape or violent antisocial responses as the only way in which the relatively deprived can express themselves. A philosopher might criticise all the previous letters by pointing out that the very notion of moral decline is incoherent since moral attitudes are irredeemably subjective and relate only to particular cultures or subcultures. The Times then rounds off the whole

Bishopthorpe, York YO2 1QE

JOHN HABGOOD, DD, PHD, the Lord Archbishop of York correspondence by saying that there is obviously a need for more research or, if a different leader writer is in charge, by blaming the Church for "its deafening silence," and complaining that the Ten Commandments are no longer read frequently enough.

We live in an age of moral confusion in which we disagree not just about our moral choices but about the basis of our moral diagnosis and the very concepts in which we try to tackle it.

\section{Voluntary guidelines?}

And the Ten Commandments? There is some sharp truth in the cartoon which showed Moses receiving the stone tablets and saying to the Lord, "You know, Lord, I think they'd gn down better if we called them voluntary guidelines."

Where then, in our confused society, can we find our moral roots, and the kind of moral guidance that we need so desperately? For those standing in the biblical tradition the answers may at first seem easy. I suspect, though, that many do not realise the sheer difficulty of applying this tradition with integrity to the problems of our very different society. To take only one example, the history of responses to the command "Thou shalt not kill" is enough to fill whole libraries. A doctor may have profound respect for human life in all its forms. Yet he may constantly have to face dilemmas about whose life must be given priority, what quality of life must be safeguarded, and so on. The commandment may provide a background, a sense that there are moral demands on us that are not just the product of our own feelings and circumstances, but it does not provide answers.

For those who do not stand in the biblical tradition, and for whom the Ten Commandments belong only to a distant religious past, there may be no less of a desire to make valid moral choices, but the uncertainties may be even more crippling. What right have we, in the absence of an agreed moral basis, to force our moral insights on to other people?

I have been painting a depressing picture. But it is not all depressing. I believe in fact that there are some moral roots in our society, roots from which we can draw nourishment, roots which go back to our religious heritage, but have survived in people who would no longer class themselves as religious. Such roots can therefore be used to sustain moral decisions right across the spectrum of our society. And that is important for a professon which has to serve everybody, irrespective of belief. Given time I believe that we could trace them back to that love of God and love of our neighbour which summarise the biblical moral tradition. But rather than try to do that, let me spell out briefly, and in more modern language, what I believe these moral roots are. 